\title{
Impact of surgical ventricular reconstruction on stroke volume in patients with ischemic cardiomyopathy
}

\author{
Marisa Di Donato, MD, ${ }^{\mathrm{a}, \mathrm{b}}$ Fabio Fantini, MD, ${ }^{\mathrm{b}}$ Anna Toso, MD, ${ }^{\mathrm{b}}$ Serenella Castelvecchio, MD, ${ }^{\mathrm{a}}$ \\ Lorenzo Menicanti, MD, ${ }^{\mathrm{a}}$ Lon Annest, MD, ${ }^{\mathrm{c}}$ and Daniel Burkhoff, MD, $\mathrm{PhD}^{\mathrm{d}}$
}

Objective: Left ventricular end-diastolic volume is decreased and ejection fraction is increased after surgical ventricular reconstruction; however, the impact on left ventricular stroke volume is not well established.

\begin{abstract}
Methods: We analyzed 248 consecutive patients who underwent surgical ventricular reconstruction at a single center. There were 14 perioperative deaths $(5.6 \%)$. The 234 surviving patients had pre- and postsurgical ventricular reconstruction echocardiographic measurement of end-diastolic volume, end-systolic volume, and stroke volume, each indexed to body size and ejection fraction. A total of 120 patients had echocardiography data at follow-up (median 8 months).
\end{abstract}

Results: Overall, surgical ventricular reconstruction resulted in reductions in end-diastolic volume index $(-30 \%$ $\pm 18 \%)$ and end-systolic volume index $(-37 \% \pm 20 \%)$, and increases in ejection fraction $(21 \% \pm 18 \%$ relative increase). However, stroke volume index decreased from $35 \pm 8 \mathrm{~mL} / \mathrm{m}^{2}$ preoperatively to $28 \pm 7 \mathrm{~mL} / \mathrm{m}^{2}$ early postoperatively (a $17 \% \pm 24 \%$ relative reduction, $P<.0001) ; 165$ patients $(71 \%)$ exhibited a decrease and 69 patients $(29 \%)$ exhibited an increase or no change in stroke volume index after surgical ventricular reconstruction. Stroke volume index reduction was strictly related to end-diastolic volume reduction. Patients who initially had a stroke volume index decrease showed recovery, so that at the time of chronic follow-up there was no significant difference between the groups. Notably, 4-year survival was approximately $85 \%$ and did not differ between patients with an increase or decrease in stroke volume index $(P=.383)$.

Conclusions: Although surgical ventricular reconstruction uniformly results in an impressive decrease in enddiastolic volume index and increase in ejection fraction, seemingly indicating beneficial remodeling and improved pump function, systolic volume index, which more directly indexes cardiac pump function, frequently decreases after surgical ventricular reconstruction. Further study is needed to identify baseline characteristics that predict those patients in whom cardiac performance is enhanced by surgical ventricular reconstruction and to clarify whether there is a beneficial impact on exercise tolerance and cardiac output at peak exercise. ( $\mathrm{J}$ Thorac Cardiovasc Surg 2010;140:1325-31)

\section{Supplemental material is available online.}

Until recently, surgical ventricular reconstruction (SVR) for ischemic cardiomyopathy, as described by Dor and colleagues, ${ }^{1,2}$ was being performed with increasing frequency to resize and reshape the dilated left ventricle (LV) caused by ischemic cardiomyopathy. Immediate reduction of LV

\footnotetext{
From the Department of Cardiac Surgery, ${ }^{\mathrm{a}}$ IRCCS, San Donato Hospital, Milan, Italy; Department of Critical Care Medicine, ${ }^{\mathrm{b}}$ University of Florence, Florence, Italy; BioVentrix, ${ }^{\mathrm{c}}$ San Ramon, Calif; and Division of Cardiology, ${ }^{\mathrm{d}}$ Columbia University, New York, NY.

Disclosures: None.

Received for publication July 6, 2009; revisions received Dec 30, 2009; accepted for publication Jan 18, 2010; available ahead of print April 12, 2010.

Address for reprints: Marisa Di Donato, MD, Department of Cardiac Surgery, IRCCS, San Donato Hospital, Via Morandi 30, 20097 San Donato Milanese (Milan), Italy (E-mail:marad@tin.it).

0022-5223/\$36.00

Copyright (C) 2010 by The American Association for Thoracic Surgery doi:10.1016/j.jtcvs.2010.01.031
}

end-systolic volume (ESV) by as much as $30 \%$ or more is typically achieved, ${ }^{2}$ far greater than the degree of reverse remodeling achieved with any other heart failure treatment. Furthermore, SVR also results in an immediate reduction in chamber radius, which decreases myocardial systolic and diastolic wall stresses (Laplace's Law) and therefore has potential, similar to pharmacologic therapies that reduce myocardial afterload and preload, to induce myocellular and molecular reverse remodeling. ${ }^{3,4}$ However, with the recent publication of the multinational Surgical Treatment for Ischemic Heart Failure (STICH) trial, ${ }^{5}$ which showed no difference in mortality, hospitalizations, symptoms, or exercise tolerance in the overall population treated with coronary artery bypass grafting (CABG) alone or CABG plus SVR, it is expected that the number of SVR procedures will decline significantly.

Before release of the STICH study results, several theoretic and experimental studies explored the impact of SVR on LV pump function. ${ }^{6-12}$ Although ejection fraction (EF) consistently increases after SVR, it has been shown that this does not have the usual meaning of an increase in 


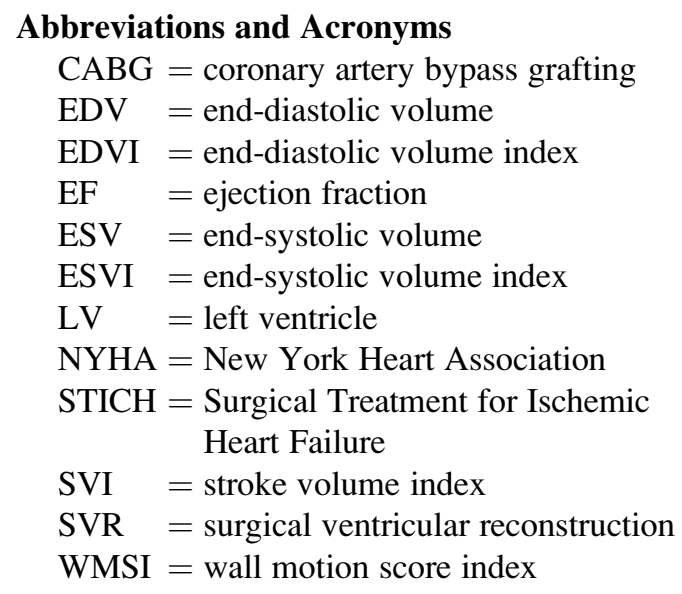

LV pump function. ${ }^{6,8}$ Among the other indexes of pump function explored, there were load-independent (eg, endsystolic pressure-volume relations) and load-dependent (eg, stroke volume) indexes. Regardless of which of these indexes was examined, the results suggested that pump function could be increased, unchanged, or decreased, depending on the relative characteristics (dyskinetic, akinetic, or hypokinetic, respectively) and amount of the LV wall excluded during SVR. Because it was anticipated that a majority of patients to be included in STICH would have akinetic scars, it was suggested prospectively that the study would be neutral with regard to clinical outcomes, which turned out to be the case. ${ }^{5,6}$ However, whether there is a direct link between the impact of SVR on LV function and clinical outcomes is speculative and remains an important unresolved question.

Therefore, the purpose of the present study was to determine how SVR affects stroke volume and, most important, to test whether acute postoperative changes in SV are associated with clinical outcome after SVR.

\section{MATERIALS AND METHODS}

This is a retrospective case review study of 248 patients with previous anterior myocardial infarction who were referred for SVR at the San Donato Hospital between October 2001 and July 2008 and who had echocardiograms before surgery and at the time of hospital discharge. A total of 120 of these patients also had echocardiograms performed at a median of 8 months after surgery. Indications for SVR were symptomatic heart failure, angina, or a combination of the 2 ; concomitant coronary grafting was performed in $94 \%$ of cases. Patients with moderate-to-severe mitral regurgitation were excluded from the present analysis; this excludes the possibility that postoperative SV estimates from LV volumes were artifactually decreased because of the increased afterload after mitral repair or replacement.

LV volumes were calculated from biplane echocardiographic images (4chamber and 2-chamber views) using the Simpson method. SV was defined as the difference between end-diastolic volume (EDV) and ESV, and, in the absence of mitral regurgitation, it represents the effective output per beat. EF was defined as $\mathrm{SV} / \mathrm{EDV} \times 100$. $\mathrm{LV}$ volume measurements were indexed to body surface area and expressed as end-diastolic volume index (EDVI), end-systolic volume index (ESVI), and stroke volume index (SVI). We are aware of the limitation of biplane echocardiography to measure LV volumes, especially in ischemic dilated heart disease and in a procedure that markedly changes LV geometry; however, the echocardiography study is performed both before and after surgery by the same experienced cardiologist, well trained in the evaluation of candidates for SVR. When there are difficulties to identify the endocardial border, we use contrast echocardiography to improve the vision of the cavity, and when the acoustic window is poor, we perform cardiac magnetic resonance but do not report the echocardiography data on the registry. Follow-up was conducted periodically through telephone interview with the family or the family doctor, and if the telephone interview failed, we contacted the regional death registry. The study was approved by our ethical committee, and patients gave their informed consent.

\section{Surgical Procedure}

Details of the surgical technique have been reported. ${ }^{2,12,14}$ In brief, the procedure is conducted on arrested hearts with antegrade crystalloid or blood cold cardioplegia. Complete coronary grafting is first performed, and then the ventricle is opened and an intraventricular device (TRI-SVR Chase Medical, Richardson, Tex) is inflated in the ventricle, according to body surface area $\left(50-60 \mathrm{~mL} / \mathrm{m}^{2}\right)$, to resize and reshape the $\mathrm{LV}$. The new apex is formed around the shaper, which is removed before closing the ventricle, with or without a patch.

\section{Statistical Analysis}

The results are expressed as mean \pm standard deviations unless otherwise indicated. Statistical analysis included an analysis of variance with Bonferroni corrections for within-group comparisons or an independent variable Student $t$ test for comparison between 2 groups. Paired $t$ testing was used to compare pre- and postoperative changes. Kaplan-Meier analysis was used to assess survival, and log-rank test was used to compare groups. The SPSS software (SPSS Inc, Chicago, Ill) was used for statistics.

\section{RESULTS}

Of the 248 patients included in the study who underwent SVR during the reporting period, 234 (95\%) survived to hospital discharge and had a predischarge echocardiogram. There was an approximately $5 \%$ perioperative mortality (14 patients) during the first 30 days. Comparison of clinical characteristics (Table E1) showed that patients who survived were slightly younger, had lower proportion of New York Heart Association (NYHA) class III or IV, and had higher EFs compared with patients who died perioperatively. There were no significant differences in gender, background medical therapies, and basic features of the surgical procedure between these 2 groups. There were no differences in heart rate that might have influenced SVI changes after SVR ( $66 \pm 9$ vs $68 \pm 8, P=.658$ ) or in the rate of hypertension among risk factors $(57 \%$ vs $52 \%, P=.662)$. Baseline angiotensin-converting enzyme inhibitor, $\beta$-blocker, and diuretic use was less than in most current heart failure trials, mainly because of the early start date of the study, which was before widespread use of these agents and the inclusion of patients with NYHA class II symptoms.

Overall, SVR resulted in reductions in EDVI $(-30 \% \pm$ $18 \%)$ and ESVI $(-37 \% \pm 20 \%)$, and increases in EF $(21 \% \pm 18 \%$ relative increase $)(P .0001)$, but a decrease in SVI $(-17 \% \pm 24 \%)$ (Figure 1). For the group as a whole, SVI decreased from $35 \pm 8 \mathrm{~mL} / \mathrm{m}^{2}$ preoperatively to 


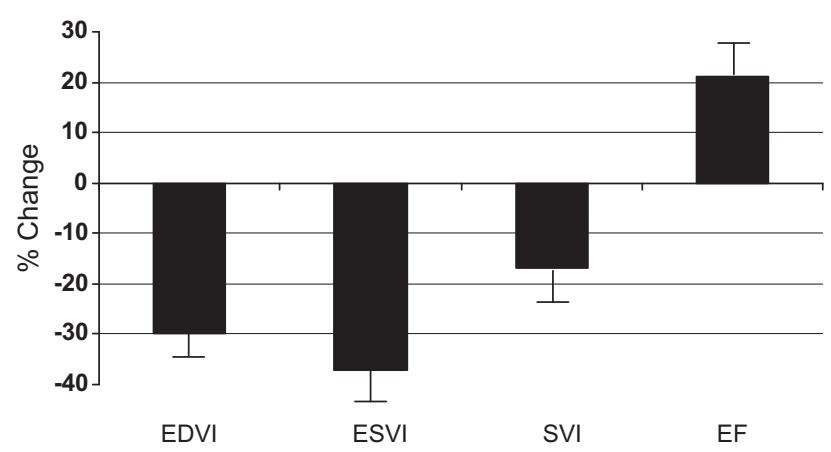

FIGURE 1. Postoperative changes in EDVI, ESVI, SVI, and EF in the overall study population. Despite increases in EF, SVI decreased. See text for details. All changes are significant at $P<.001$. EDVI, End-diastolic volume index; $E S V I$, end-systolic volume index; $S V I$, stroke volume index; $E F$, ejection fraction.

$28 \pm 7 \mathrm{~mL} / \mathrm{m}^{2}$ postoperatively $(P<.0001)$. However, the response was heterogeneous in that SVI decreased in 165 $(71 \%)$ of the patients and increased in $69(29 \%)$ of the patients after SVR. The relationship between changes in EDVI and changes in EF and SVI are summarized in Figure 2, with variables expressed as percent changes from baseline. For the group as a whole, the greater the reduction in EDVI, the greater the increase in $\mathrm{EF}$ and the greater the decrease in SV. Changes in EF were highly correlated to changes in EDVI $(r=0.89)$. In comparison, the relationship between changes in EDVI and SVI had a lower correlation coefficient $(r=0.63)$, and there was significantly more scatter around the line of regression. It is seen that although the trend was for SVI to decrease as EDVI decreased, even with large reductions in EDVI there were some patients in whom SVI was unchanged or even increased.

To explore if there was any systematic impact of the absolute size of the heart at baseline on the impact of SVR on postoperative LV size and function, patients were grouped into quintiles of baseline EDVIs as follows: category I, $\leq 86 \mathrm{~mL} / \mathrm{m}^{2}$; category II, $86-105 \mathrm{~mL} / \mathrm{m}^{2}$; category III, $106-126 \mathrm{~mL} / \mathrm{m}^{2}$; category IV, $127-169 \mathrm{~mL} / \mathrm{m}^{2}$; and category $\mathrm{V}, \geq 169 \mathrm{~mL} / \mathrm{m}^{2}$. The pre- and postoperative LV size and function data are summarized in Table 1 according to these categories. In all categories, SVR significantly reduced ESVI and EDVI and increased EF. However, except for category I (relatively smaller hearts at baseline), average SVI decreased in all categories $\left(7-11 \mathrm{~mL} / \mathrm{m}^{2}\right)$, and there was a trend for the decrease in SVI to be greater in the larger hearts.

\section{Long-Term Changes in Left Ventricular Size and Function}

In 120 patients, echocardiograms were available at baseline, 1 week post-SVR, and a median of 8 months (range 4-58 months) after SVR. The patients excluded from the present analysis (because they did not have echocardiography control at follow-up) did not differ in clinical and hemodynamic profiles from the 120 patients with echocardiography control. Patients in whom SV decreased initially had larger stroke volumes at baseline compared with those in whom SV increased initially (Figure 3); they also had larger EDVI and ESVI and greater EF $(35 \% \pm 7 \%$ vs $31 \% \pm 8 \% ; P .004)$ However, the SVI reduction was temporary, and patients in whom SV had initially decreased showed recovery, so that at the time of chronic follow-up there was no significant difference in SV between the groups (Table 2). The reduction in EDVI and ESVI persisted along time (EDVI from $114 \pm 42 \mathrm{~mL} / \mathrm{m}^{2}$ to $82 \pm 20 \mathrm{~mL} / \mathrm{m}^{2}$; ESVI from $76 \pm 37 \mathrm{~mL} / \mathrm{m}^{2}$ to $49 \pm 18 \mathrm{~mL} / \mathrm{m}^{2}, P .001$ vs baseline), indicating a persistent benefit. These findings indicate that different baseline loading conditions may impact the response of cardiac function to SVR.

\section{Impact of Properties of Excluded Region}

Prior studies have suggested that the impact of SVR on stroke volume will vary with the amount and material
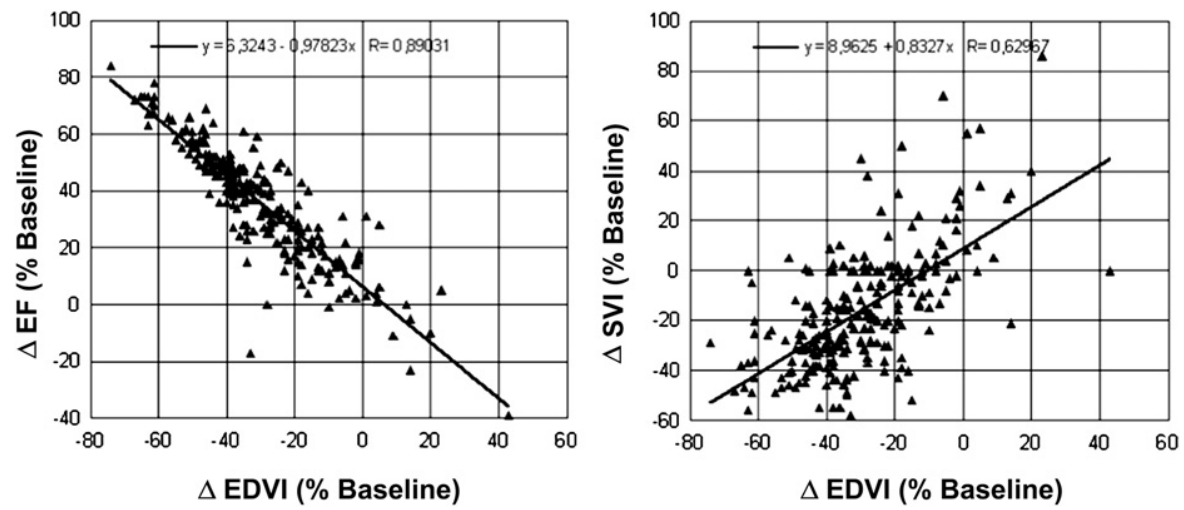

FIGURE 2. The relationships between changes in EDVI and changes in EF and SVI variables are expressed as percent changes from baseline. Changes in EF were highly correlated to changes in EDVI $(\mathrm{r}=0.89)$. In comparison, the relationship between changes in EDVI and SVI had a lower correlation coefficient $(r=0.63)$, and there was significantly more scatter around the line of regression. Notably, there were many patients in whom SVI was unchanged or even increased. $E D V I$, End-diastolic volume index; $S V I$, stroke volume index; $E F$, ejection fraction. 
TABLE 1. Impact of surgical ventricular restoration on left ventricular size and function with patients grouped in quintiles of preoperative enddiastolic volume index

\begin{tabular}{|c|c|c|c|c|c|c|c|c|c|c|}
\hline & \multicolumn{2}{|c|}{$\begin{array}{c}\text { Category I } \\
\text { EDVI }_{\text {pre }} \leq \mathbf{8 6} \\
\mathbf{N}=\mathbf{3 0} \\
\end{array}$} & \multicolumn{2}{|c|}{$\begin{array}{c}\text { Category II } \\
86<\text { EDVI }_{\text {pre }} \leq 105 \\
\mathbf{N}=\mathbf{6 0}\end{array}$} & \multicolumn{2}{|c|}{$\begin{array}{c}\text { Category III } \\
105<\text { EDVI }_{\text {pre }} \leq 126 \\
N=67\end{array}$} & \multicolumn{2}{|c|}{$\begin{array}{c}\text { Category IV } \\
126<\text { EDVI }_{\text {pre }} \leq 169 \\
\mathrm{~N}=64\end{array}$} & \multicolumn{2}{|c|}{$\begin{array}{c}\text { Category V } \\
\text { EDVI }_{\text {pre }} \geq 169 \\
\mathbf{N}=13 \\
\end{array}$} \\
\hline & Pre & Post & Pre & Post & Pre & Post & Pre & Post & Pre & Post \\
\hline $\operatorname{EDVI}\left(\mathrm{mL} / \mathrm{m}^{2}\right)$ & $73 \pm 9$ & $59 \pm 15^{*}$ & $95 \pm 5$ & $69 \pm 18^{*}$ & $114 \pm 6$ & $73 \pm 16^{*}$ & $142 \pm 13$ & $93 \pm 23^{*}$ & $200 \pm 34$ & $98 \pm 21^{*}$ \\
\hline $\operatorname{ESVI}\left(\mathrm{mL} / \mathrm{m}^{2}\right)$ & $44 \pm 8$ & $32 \pm 11^{*}$ & $61 \pm 7$ & $41 \pm 14^{*}$ & $78 \pm 10$ & $45 \pm 13^{*}$ & $101 \pm 14$ & $61 \pm 19^{*}$ & $159 \pm 33$ & $67 \pm 18^{*}$ \\
\hline $\mathrm{SVI}\left(\mathrm{mL} / \mathrm{m}^{2}\right)$ & $30 \pm 7$ & $27 \pm 7$ & $34 \pm 5$ & $27 \pm 7^{*}$ & $37 \pm 7$ & $28 \pm 7^{*}$ & $41 \pm 8$ & $31 \pm 7^{*}$ & $41 \pm 9$ & $30 \pm 5^{*}$ \\
\hline EF \% & $40 \pm 7$ & $46 \pm 10^{*}$ & $35 \pm 6$ & $41 \pm 8 *$ & $32 \pm 7$ & $38 \pm 8^{*}$ & $29 \pm 6$ & $35 \pm 6^{*}$ & $21 \pm 6$ & $32 \pm 6^{*}$ \\
\hline
\end{tabular}

$E D V I$, End-diastolic volume index; $E S V I$, end-systolic volume index; $S V I$, stroke volume index; $E F$, ejection fraction. $* P<.001$ vs preoperatively.

properties of the scar that is excluded (akinetic vs dyskinetic). We used a standard semiquantitative 4-point wall motion score index (WMSI) to characterize the segment(s) that was surgically excluded and related this to the change in stroke volume. The WMSI scale was as follows: $1=$ normal wall motion, $2=$ hypokinesia, $3=$ akinesia,
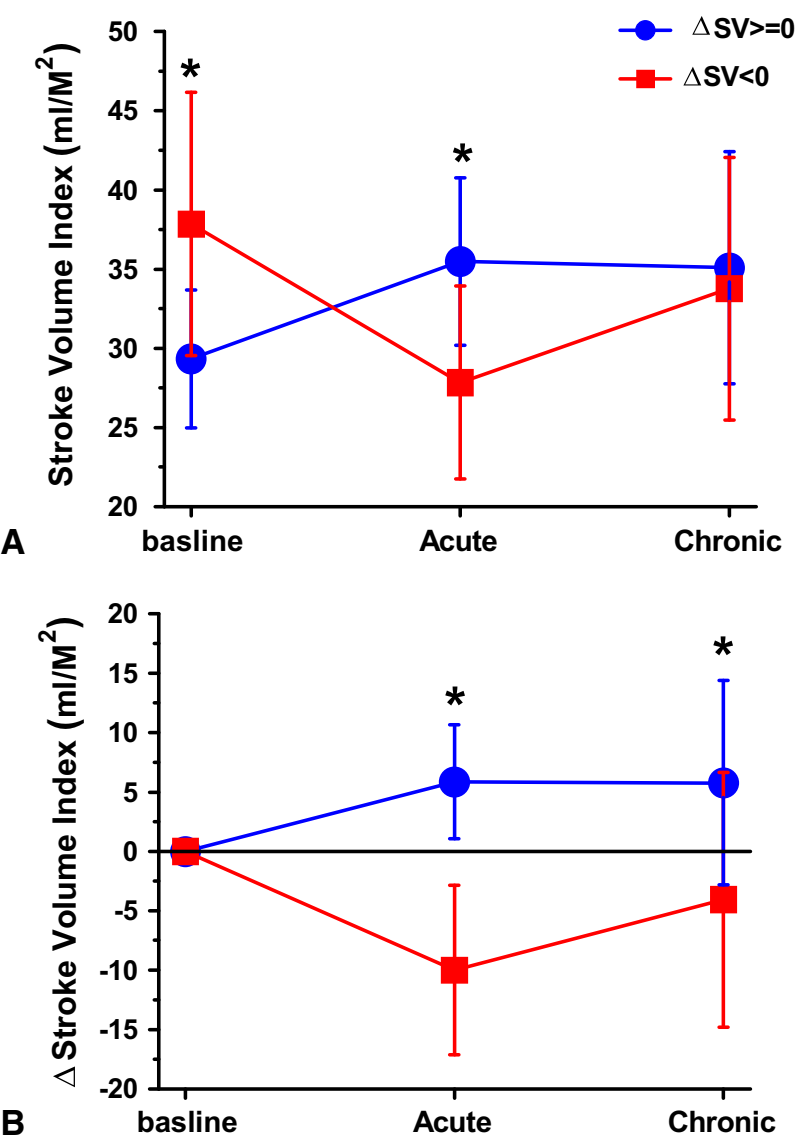

FIGURE 3. A total of 120 patients were followed for a median of 8 months. Patients with an initial decrease in SV had larger stroke volumes at baseline compared with patients with an initial increase in SV. However, patients with an initial decrease in SV showed recovery, so at the time of chronic follow-up, there was no significant difference in SV between the groups. $* P<.001$ between groups. $S V$, Stroke volume. and $4=$ dyskinesia. A significant inverse correlation between WMSI and SVI changes (Pearson $r=-0.2741 ; 95 \%$ confidence interval, -0.4797 to $-0.03998 ; P=.026$ ) was observed; thus, the higher the WMSI (ie, the more dyskinetic the segment) the less the reduction in SVI after SVR. Furthermore, the WMSI of the patients with increased SVI $(2.52 \pm 0.30)$ was significantly greater than in the patients with decreased SVI $(2.35 \pm 0.28, P=.01)$.

\section{Survival and Clinical Correlates}

We assessed whether early SV increase or decrease affected clinical status or survival after SVR and found NYHA functional class improved at follow-up, independently of whether SVI decreased (from $2.4 \pm 0.7$ to $1.6 \pm$ $0.7, P<.0001$ ) or increased (from $2.4 \pm 0.7$ to $1.5 \pm 0.6$, $P<.0001$ ). Moreover, with an average of $43 \pm 24$ months follow-up, there was no difference in survival between these 2 groups (Figure E1, $P=.383,97 \%$ follow-up). Overall survival at 4 years was approximately $90 \%$; even if the approximately $5 \%$ perioperative mortality is included, the

TABLE 2. Hemodynamic changes at three time intervals

\begin{tabular}{lccc}
\hline & SVI decreased & SVI increased & $P$ value \\
\hline EDVI $\left(\mathrm{mL} / \mathrm{m}^{2}\right)$ & & & \\
Pre & $114 \pm 42$ & $100 \pm 30$ & .02 \\
Early post & $71 \pm 20$ & $82 \pm 21$ & .001 \\
Late post & $82 \pm 20$ & $91 \pm 28$ & .09 \\
ESVI $\left(\mathrm{mL} / \mathrm{m}^{2}\right)$ & & & \\
Pre & $76 \pm 37$ & $70 \pm 29$ & .524 \\
Early post & $43 \pm 16$ & $48 \pm 18$ & .07 \\
Late post & $49 \pm 17$ & $57 \pm 27$ & .08 \\
SVI (mL/m $\left.{ }^{2}\right)$ & & & \\
Pre & $38 \pm 9$ & $29 \pm 6$ & .001 \\
Early post & $27 \pm 6$ & $34 \pm 7$ & .001 \\
Late post & $33 \pm 7$ & $33 \pm 7$ & .724 \\
EF $(\%)$ & & & \\
Pre & $35 \pm 8$ & $31 \pm 8$ & .004 \\
Early post & $40 \pm 9$ & $42 \pm 9$ & .524 \\
Late post & $41 \pm 8$ & $40 \pm 10$ & .734 \\
\hline
\end{tabular}

$S V I$, Stroke volume index; $E D V I$, end-diastolic volume index; $E S V I$, end-systolic volume index; $E F$, ejection fraction. 
total mortality amounts to an approximately $85 \%$ 4-year survival.

\section{DISCUSSION}

The results of the present study show that despite a consistent increase in EF, resting SV frequently decreases after SVR. In fact, data pooled from the entire cohort showed an average $7 \mathrm{~mL} / \mathrm{m}^{2}(17 \%)$ decrease in resting SV. Prior clinical studies of SVR have emphasized the decrease in EDV and ESV and the increase in EF that are always observed after SVR. It was these specific observations that largely fueled clinical enthusiasm for SVR. However, it has been emphasized that the meaning of the changes in these variables is not the same as it is when they are achieved by pharmacologic or device-based therapies in which reductions in $\mathrm{LV}$ volumes and mass result from regression of hypertrophy at a cellular level. ${ }^{6,7}$ Rather than focusing on the impact on EF, EDV, and ESV, however, it has been suggested that attention be directed to the impact of SVR on variables that more directly index pump function, such as cardiac work, stroke volume, and cardiac output.

Overall, SVR was performed with relative safety $(\sim 5 \%$ perioperative mortality) and high long-term survival. $\mathrm{Pa}-$ tients who died perioperatively were older and had clinical and echocardiographic evidence of worse heart failure compared with the remaining patients. However, one of the most important aspects of the current findings is that overall survival was not affected by whether stroke volume increased or decreased after SVR. Although there is no a priori reason to expect that survival would be linked with a change in resting $\mathrm{SV}$, it is reasonable to be concerned that there could have been negative consequences.

A detailed review of the literature ${ }^{11}$ indicates that the current findings regarding a reduction in SV from SVR are not unexpected. A survey of 31 articles in which LV volumes where reported pre- and post-SVR reveals that several investigators noted a reduction in $\mathrm{SV}^{10-17}$ and others reported an increase in SV. ${ }^{18-24}$ It is noteworthy that although these articles always reported pre- and post-SVR values for LVEDVs and EFs, values for SVs were not typically reported, and, more specifically, changes in SV were almost never reported (or discussed). Because of the lack of such reporting, a formal meta-analysis of the impact of SVR on SVI is not possible. Inconsistent reporting of data completeness, differences in volume measurement techniques, and significant differences in the timing of postoperative volume measurements further complicate performance of such a meta-analysis. Overall, our estimates of mean postSVR changes in SV reported in the literature ${ }^{11}$ range from an increase of $15 \mathrm{~mL}$ to decreases of $15 \mathrm{~mL}$ or greater with, as noted above, a majority of studies showing reductions. This survey of the literature indicates that the findings of our current study are not inconsistent with the majority of prior reports.
The present study analyzed the early changes in SVI after SVR and attempted to understand the apparent paradox of improved volumes reduction and EF with the frequently observed reduction in stroke volume after SVR. Our data indicate that "early" stroke volume reduction is transitory (Figure 3) and is linked, at least partially, to preoperative ventricular properties. Patients with an SVI decrease had a higher preoperative stroke volume and larger EDV. Notably, these patients also had a lower WMSI, indicating significantly less wall motion abnormalities. As detailed previously, ${ }^{6}$ this fits with the theory showing that with regard to the impact on pump function, SVR could be detrimental in patients whose wall to be excluded is hypokinesia, would be neutral in patients whose wall to be excluded is akinetic, and would be beneficial in patients whose wall to be excluded is dyskinetic. Thus, the higher the WMSI, the greater the expected improvement in stroke volume.

\section{Limitations}

There are several limitations of the present study. First, we only measured echocardiograms at rest. If SVR chronically reduces wall stress and improves inotropic reserve, chronotropic competence, and myocardial force-frequency relations, there could be a disparity between an impact at rest and during stress. It would be interesting to pursue these hypotheses in future studies. Second, our most complete data set concerning the impact of SVR on LV size and function was in the early postoperative period, with a smaller database at long-term follow-up. Comparison of resting LV size and function between preoperative and early postoperative conditions provides important information about the direct effects of the surgery. It would have been ideal to have a more thorough database at a consistent, long-term follow-up period. However, because this was a registry study, we were limited to information obtainable in the routine course of care of these patients, which did not always include long-term echocardiograms. In addition, we did not collect information about patient blood pressure at the time of echocardiogram, at either short term or long term. Significant changes in blood pressure could have an impact on stroke volume and thus on the conclusions of the present study. Evaluation of load-independent indexes of ventricular contractility could have provided information significantly beyond that provided simply by EDV, SV, and EF. Such indexes typically evaluate SV, stroke work, end-systolic pressures, and ESVs over a range of filling conditions, information that is not available from the present cohort. Such information has been provided in prior studies, ${ }^{10}$ mainly in the short-term period after surgery. These studies confirm important and specific changes in LV systolic and diastolic properties. ${ }^{6}$ In this regard, it would be most interesting to investigate whether specific changes in such load-independent indexes correlate with outcome, which has not been done thus far. Third, the percentage of patients prescribed 
angiotensin-converting enzyme inhibitors or $\beta$-blockers was low compared with current standards, and this may have affected both SV (another reason why load-independent indexes of LV function would be ideal) and clinical outcomes. The low use of these drugs is explained by the early start date of this registry, which was significantly before the widespread use of these drugs. Finally, the present cohort was not evaluated rigorously for changes in quality of life or other heart failure-related clinical events, such as the rates of hospitalization. Such factors could be more directly affected by changes in SV than mortality.

The recently released results of the STICH trial showed that SVR in combination with CABG had no impact over CABG alone on mortality, heart failure hospitalizations, exercise tolerance, or quality of life. ${ }^{5}$ Several major limitations of the STICH trial have already been noted, ${ }^{25}$ including (1) patient inclusion bias (ie, many patients whose primary surgeons considered SVR to be clinically indicated were not randomized, characterized, or studied) and (2) a much smaller than planned average reduction of EDV in the SVR group (raising serious questions about whether the procedure was performed properly in a majority of cases). Nevertheless, the overwhelmingly neutral results of that study mandate that additional studies of SVR be carried out to define its role in the care of patients with ischemic cardiomyopathy. It is reasonable to believe that after the STICH results, a widespread application of SVR to all patients with ischemic cardiomyopathy is not warranted, and yet it is still reasonable to hypothesize that a definable group of patients exist who could benefit from SVR. Further clarification of (1) ventricular properties associated with better hemodynamic effects of SVR and (2) links between hemodynamic effects and clinical outcomes could help define appropriate patient selection criteria for this procedure.

\section{CONCLUSIONS}

Because of several limitations of the STICH trial, ${ }^{5}$ it is expected that SVR will continue to be performed in many centers, albeit possibly with reduced frequency. Investigators will undoubtedly be motivated to understand factors that identify patients who will benefit from this procedure. The results of the present study potentially provide additional insights by revealing that SVR can commonly result in a decrease in resting SV. The dissociation between reductions in SV and overall survival is reassuring but does not preclude an impact on other important aspects of overall patient well-being. We identified baseline characteristics of the excluded region (ie, the degree of dyskinesia) that correlated with the impact on SV, although the correlation was not strong. We hypothesize, as suggested by theory, that more detailed characterization of the excluded and non-excluded regions, for example, as could be available from modern magnetic resonance imaging, will lead to improved understanding of this matter. In addition, consistency of the surgi- cal reconstruction procedure to reach target volumes, assessment of additional measures of quality of life, and, perhaps most important, assessment of exercise tolerance and cardiac output at peak exercise would be important aspects of future studies of SVR.

\section{References}

1. Dor V, Saab M, Coste P, Kornaszewska M, Montiglio F. Left ventricular aneurysm: a new surgical approach. Thorac Cardiovasc Surg. 1989;37:11-9.

2. Dor V, Sbatier M, DiDonato M, Montiglio F, Toso A, Maioli M. Efficacy of endoventricular patchplasty in large post-infarction akinetic scar and severe left ventricular dysfunction: comparison with a series of large dyskinetic scars. $J$ Thorac Cardiovasc Surg. 1998;116:50-9.

3. Liden H, Karason K, Bergh CH, Nilsson F, Koul B, Wiklund L. The feasibility of left ventricular mechanical support as a bridge to cardiac recovery. Eur J Heart Fail. 2007;9:525-30.

4. Bruggink AH, van Oosterhout MF, de Jonge N, Ivangh B, van Kuik J, Voorbij RH, et al. Reverse remodeling of the myocardial extracellular matrix after prolonged left ventricular assist device support follows a biphasic pattern. J Heart Lung Transplant. 2006;25:1091-8.

5. Jones RH, Velazquez EJ, Michler RE, Sopko G, Oh JK, O'Connor CM, et al. Coronary bypass surgery with or without surgical ventricular reconstruction. $N$ Engl $J$ Med. 2009;360:1705-17. Epub 2009 Mar 2.

6. Artrip JH, Oz M, Burkhoff D. Left ventricular volume reduction surgery for heart failure: a physiologic perspective. J Thorac Cardiovasc Surg. 2001;122:775-82.

7. Burkhoff D, Wechsler AS. Surgical ventricular remodeling: a balancing act on systolic and diastolic properties. J Thorac Cardiovasc Surg. 2006;132:459-63.

8. Ratcliffe MB, Guy TS. The effect of preoperative diastolic dysfunction on outcome after surgical ventricular remodeling. J Thorac Cardiovasc Surg. 2007; $134: 280-3$

9. Tulner SA, Steendijk P, Klautz RJ, Tops L, Bax JJ, Versteegh MI, et al. Clinical efficacy of surgical heart failure therapy by ventricular restoration and restrictive mitral annuloplasty. J Card Fail. 2007;13:178-83.

10. Tulner SA, Bax JJ, Bleeker GB, Steendijk P, Klautz RJ, Holman ER, et al. Beneficial hemodynamic and clinical effects of surgical ventricular restoration in patients with ischemic dilated cardiomyopathy. Ann Thorac Surg. 2006;82:1721-7.

11. Annest L, Burkhoff D, Jorde U, Wechsler AS. Stroke volume alterations in patients undergoing left ventricular reconstructive surgery: a meta-analysis of 2,131 cases. J Card Fail. 2007;3:S118.

12. Menicanti L, Di Donato M. The Dor procedure: what has changed after fifteen years of clinical practice? J Thorac Cardiovasc Surg. 2002;124:886-90.

13. Di Donato M, Toso A, Dor V, Sabatier M, Barletta G, Menicanti L, et al. Surgical ventricular restoration improves mechanical intraventricular dyssynchrony in ischemic cardiomyopathy. Circulation. 2004;109:2536-43.

14. Menicanti L, Castelvecchio S, Ranucci M, Frigiola A, Santambrogio C, de Vincentiis C, et al. Surgical therapy for ischemic heart failure: single-center experience with surgical anterior ventricular restoration. J Thorac Cardiovasc Surg. 2007; 134:433-41.

15. Cirillo M, Amaducci A, Brunelli F, Dalla TM, Parrella P, Tasca G, et al. Determinants of postinfarction remodeling affect outcome and left ventricular geometry after surgical treatment of ischemic cardiomyopathy. $J$ Thorac Cardiovasc Surg. 2004; 127:1648-56.

16. Patel ND, Williams JA, Nwakanma LU, Weiss ES, Conte JV. Impact of lateral wall myocardial infarction on outcomes after surgical ventricular restoration. Ann Thorac Surg. 2007;83:2017-27.

17. O'Neill JO, Starling RC, McCarthy PM, Albert NM, Lytle BW, Navia J, et al. The impact of left ventricular reconstruction on survival in patients with ischemic cardiomyopathy. Eur J Cardiothorac Surg. 2006;30:753-9.

18. Patel ND, Williams JA, Barreiro CJ, Bonde PN, Waldron MM, Chang DC, et al. Surgical ventricular remodeling for multiterritory myocardial infarction: defining a new patient population. J Thorac Cardiovasc Surg. 2005;130:1698-706.

19. Suma H, Isomura T, Horii T, Sato T, Kikuchi N, Iwahashi K, et al. Nontransplant cardiac surgery for end-stage cardiomyopathy. I Thorac Cardiovasc Surg. 2000; 119:1233-44.

20. Yamaguchi A, Adachi H, Kawahito K, Murata S, Ino T. Left ventricular reconstruction benefits patients with dilated ischemic cardiomyopathy. Ann Thorac Surg. 2005;79:456-61.

21. Dor V, Sabatier M, Montiglio F, Coste P, Di DM. Endoventricular patch reconstruction in large ischemic wall-motion abnormalities. J Card Surg. 1999;14:46-52. 
22. Athanasuleas CL, Stanley AW Jr, Buckberg GD, Dor V, DiDonato M, Blackstone EH. Surgical anterior ventricular endocardial restoration (SAVER) in the dilated remodeled ventricle after anterior myocardial infarction. RESTORE group. Reconstructive Endoventricular Surgery, returning Torsion Original Radius Elliptical Shape to the LV. J Am Coll Cardiol. 2001;37: 1199-209.

23. Ribeiro GA, da Costa CE, Lopes MM, Albuquerque AN, Antoniali F, Reinert GA, et al. Left ventricular reconstruction benefits patients with ischemic cardiomyopathy and non-viable myocardium. Eur J Cardiothorac Surg. 2006;29: 196-201.

24. Yu HY, Chen YS, Tseng WY, Chi NS, Wang CH, Wang SS, et al. Why is the surgica ventricular restoration operation effective for ischemic cardiomyopathy? Geometric analysis with magnetic resonance imaging of changes in regional ventricular function after surgical ventricular restoration. J Thorac Cardiovasc Surg. 2009;137:887-94.

25. Eisen HJ. Surgical ventricular reconstruction for heart failure. $N$ Engl J Med. 2009;360:1781-4. Epub 2009 Mar 29. 


\section{Kaplan Meier Survival Analysis by SV changes}

Following SVR: All Cause Mortality

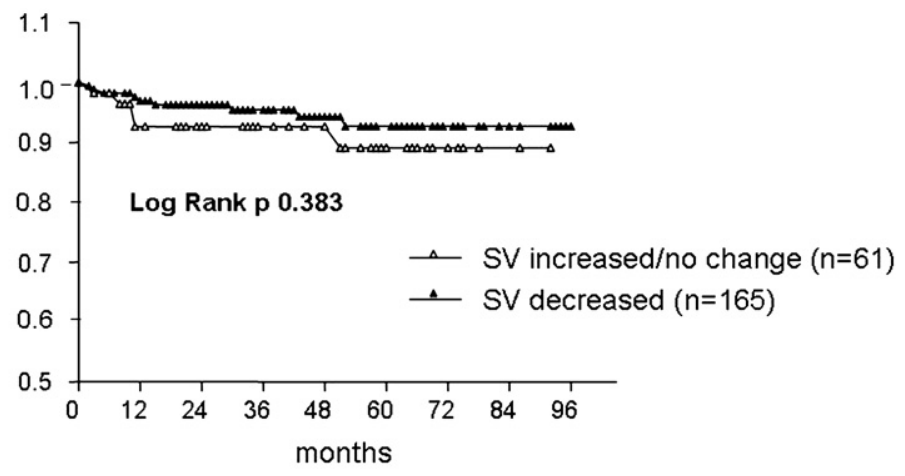

\begin{tabular}{|l|l|l|l|l|l|l|l|l|l|}
\cline { 2 - 9 } & & 0 & 12 & 24 & 36 & 48 & 60 & 72 & 84 \\
\cline { 2 - 10 } Subjects at risk & $\mathrm{N}=$ & 61 & 51 & 43 & 32 & 27 & 18 & 6 & 2 \\
\cline { 2 - 10 } Subjects at risk & $\mathrm{N}=$ & 165 & 155 & 124 & 100 & 74 & 50 & 21 & 11 \\
\cline { 2 - 9 } & & & & & & & &
\end{tabular}

FIGURE E1. Kaplan -Meier survival curves in patients whose stroke volume initially decreased compared with those whose stroke volume was initially unchanged or improved. Survival is not significantly different in the 2 groups. $S V$, Stroke volume; $S V R$, surgical ventricular restoration. 
TABLE E1. Baseline demographics, medical treatments, and surgical procedural characteristics

\begin{tabular}{|c|c|c|c|c|c|}
\hline & \multicolumn{2}{|c|}{$\begin{array}{l}\text { Survivors } \\
(n=234) \\
\end{array}$} & \multicolumn{2}{|c|}{$\begin{array}{c}\text { Nonsurvivors } \\
(n=14) \\
\end{array}$} & \multirow[b]{2}{*}{$P$ value } \\
\hline & Values & $\%$ & Values & $\%$ & \\
\hline Age (y) & $65 \pm 9$ & & $69 \pm 9$ & & .043 \\
\hline Male/female & $192 / 42$ & $82 / 18$ & $11 / 3$ & $78 / 22$ & \\
\hline \multicolumn{6}{|l|}{ Previous anterior MI } \\
\hline All MI, s & 234 & 100 & 14 & 100 & \\
\hline Q-wave MI, s & 163 & 70 & 7 & 50 & \\
\hline NYHA class & $2.7 \pm 1.7$ & & $3.1 \pm 0.7$ & & .0003 \\
\hline I & 16 & 7 & 0 & 0 & \\
\hline II & 120 & 51 & 3 & 21 & \\
\hline III & 88 & 38 & 7 & 50 & \\
\hline IV & 10 & 4 & 4 & 29 & \\
\hline \multicolumn{6}{|l|}{ Angina } \\
\hline Stable & 90 & 38 & 4 & 29 & \\
\hline Unstable & 40 & 17 & 3 & 21 & \\
\hline None & 104 & 45 & 7 & 50 & \\
\hline $\mathrm{EF}(\%)$ & $33 \pm 5$ & & $27 \pm 9$ & & .0019 \\
\hline \multicolumn{6}{|l|}{ Medical therapy } \\
\hline ACE inhibitors & 190 & 81 & 12 & 88 & \\
\hline$\beta$-blockers & 154 & 66 & 9 & 64 & \\
\hline Aspirin & 175 & 75 & 10 & 71 & \\
\hline Diuretics & 166 & 71 & 12 & 88 & \\
\hline Statins & 109 & 47 & 5 & 36 & \\
\hline \multicolumn{6}{|l|}{ SVR procedure } \\
\hline Concomitant $\mathrm{CABG}$ & 220 & 94 & 12 & 85 & \\
\hline Anastomoses & $2.7 \pm 1.4$ & & $2.9 \pm 1.2$ & & \\
\hline Patch & 155 & 66 & 10 & 72 & \\
\hline
\end{tabular}

